\title{
SISTEM PENDUKUNG KEPUTUSAN PENENTUAN JURUSAN DENGAN METODE MULTI FACTORY EVALUATION PROCESS (MFEP) (STUDI KASUS : SMK CIBENING)
}

\author{
Abdul Aziz Muhidin ${ }^{1}$, Endra Suseno, ${ }^{2,}$ Sugeng Supriyadi ${ }^{3}$ \\ Fakultas Ilmu Komputer Universitas Kuningan \\ Kampus I : Jalan Cut Nyak Dhien 36A Kuningan \\ Email : ajozmuhidin@gmail.com¹, endra@uniku.ac.id
}

\begin{abstract}
SMK Cibening merupakan salah satu sekolah di desa Cibingbin Kecamatan Cibingbin Kabupaten Kuningan. Proses penjurusan ini dimaksudkan agar nanti siswa dapat menyelesaikan sekolah sesuai dengan kemampuannya sebelum melanjutkan ke jenjang yang lebih tinggi yaitu perguruan tinggi. Proses penjurusan saat ini memiliki kelemahan diantaranya belum tersedianya program aplikasi khusus untuk mendukung perhitugan, dalam membantu Guru BK untuk menentukan penjurusan yang tepat, sehingga dalam prosesnya membutuhkan waktu cukup lama dan juga bisa saja terjadi banyak pertimbangan.Untuk mengatasi masalah tersebut maka dibuatkan sistem pendukung keputusan untuk membantu Guru BK dalam menentukan jurusan siswa-siswi di SMK Cibening. Dalam penelitian ini menggunakan metode Multifactor Evaluation Process (MFEP). Adapun kriteria yang digunakan adalah nilai raport, nilai surat keterangan hasil ujian nasional (SKHUN) dan tes kejurusan. Hasil akhir dari penelitian ini didapatkan bahwa sistem pendukung keputusan dengan metode Multifactor Evaluation Process (MFEP) mampu mengatasi permasalahan dalam proses menentukan jurusan di SMK Cibening.
\end{abstract}

Kata kunci: sistem pendukung keputusan, WATERFALLl, Dengan Metode Multifactor Evaluation Process (MFEP).

Smk Cibening is one of the schools in Cibingbin village, Cibingbin District, Kuningan Regency. The process of this course is intended so that the students can complete the school according to their abilities before continuing to a higher level, namely college. The current process of majors has disadvantages including the unavailability of special application to support courtesy, in helping counseling teachers to determine the right direction, so that the process takes a long time and also can occur a lot of consideration. to help the teachers in determining the majors of students at SMK Cibening. This study uses the Multifactor Evaluation Process (MFEP) method. The criterias used are report cards, national examination results (SKHUN) and majors. The final results of this study found that the decision support system with the Multifactor Evaluation Process (MFEP) method is able to overcome the problems in the process of determining the majors at SMK Cibening.

Keywords: decision support system, WATERFALLl, with Multifactor Evaluation Process (MFEP) Method.

\section{Pendahuluan}

Penjurusan ini dimaksudkan agar nanti siswa dapat menyelesaikan sekolah sesuai dengan kemampuannya sebelum melanjutkan ke jenjang yang lebih tinggi yaitu perguruan tinggi. Di sekolah ini terdiri dari tiga jurusan yaitu jurusan Teknik Sepeda Motor, Teknik Jaringan dan Komputer serta Akuntansi.
Proses penjurusan di SMK Cibening ini dilakukan oleh Guru BK.

Proses penjurusannya diawali setelah siswa dinyatakan diterima disekolah SMK Cibening. Setelah itu guru bimbingan konseling atau BK mengumpulkan fotocopy surat keterangan hasil ujian nasioanal (SKHUN) dan fotocopy raport masing- 
masing siswa-siswi sesuai dengan yang disyaratkan, kemudian guru BK menentukan penjurusan dengan menggunakan perhitungan secara manual, sehingga perlu mengkoreksi, mengakumulasi dan mempertimbangkan hasil dan mempertimbangkan hasil penilaiannya satu persatu dari setiap data siswa yang nantinya dijadikan dasar untuk ditentukan penjurusan. Proses penjurusan dengan cara tersebut memiliki kelemahan diantaranya membutuhkan waktu cukup lama dan juga belum tersedianya program (aplikasi) khusus untuk mendukung perhitungan tersebut. Oleh karena itu diperlukannya sebuah aplikasi sistem penunjang keputusan untuk membantu Guru BK dalam menentukan penjurusan yang tepat bagi siswa-siswi di Cibening. Sistem Pendukung Keputusan (SPK) diharapkan mampu dalam membantu pihak sekolah dalam menentukan penjurusan berdasarkan kriteria, dalam membuat keputusan.

Metode Multifactor Evaluation Process (MFEP) cocok diterapkan dalam sistem pendukung keputusan penjurusan, untuk menghitung serta memberikan hasil keputusan secara subyektif dan intuitif menimbang berbagai faktor yang mempunyai pengaruh penting terhadap alternatif pilihan. Dari komparasi tersebut menghasilkan nilai evaluasi atau weighted evaluation, sehingga dapat menentukan pemilihan keputusan secara tepat, sistem ini dimaksudkan untuk membantu pihak sekolah dalam mengambil sebuah keputusan secara lebih cepat dan tepat, sesuai dengan kriteria yang diinginkan. Alternatifalternatif pilihan diharapkan dapat memberikan daftar referensi kepada pembuat keputusan sebelum benar-benar mengambil suatu keputusan akhir. [1]
Berdasarkan latar belakang masalah di atas, maka ditemukan masalah-masalah sebagai berikut :

Belum tersedianya program khusus untuk mendukung perhitungan, dalam membantu panitia atau guru BK dalam menentukan penjurusan yang tepat, sehingga dalam proses tersebut membutuhkan waktu cukup lama dan juga bisa saja terjadi banyak kekeliruan. Proses penentuan jurusan di SMK Cibening masih dilakukan secara manual ataupun konvensional karena masih berupa rekapan.

Agar tidak menyimpang jauh dari permasalahan, maka tugas akhir ini mempunyai batasan masalah sebagai berikut :

Pada sistem pendukung keputusan ini hanya untuk melakukan penentuan jurusan penerimaan siswa baru.

Sistem pendukung keputusan menggunakan metode Multifactor Evaluation Process (MFEP).

Data yang digunakan dalam metode ini yaitu data dari nilai akademik SKHUN, nilai raport serta potensi siswa dari tes kejursan dan prestasi.

\section{Teori Dasar}

\subsection{Metode Multifactor Evaluation Process (MFEP)}

Metode Multifactor Evaluation Process (MFEP) menentukan bahwa alternatif dengan nilai tertinggi adalah solusi terbaik berdasarkan kriteria yang telah dipilih. Proses perhitungan menggunakan metode Multifactor Evaluation Process (MFEP) yaitu:

1. Menentukan faktor dan bobot faktor dimana total pembobotan harus sama dengan $1(\Sigma$ pembobotan $=1)$, yaitu factor weight.

2. Mengisikan nilai untuk setiap factor yang mempengaruhi dalam 
pengambilan keputusan dari data-data yang akan diproses, nilai yang dimasukkan dalam proses pengambilan keputusan merupakan nilai objektif, yaitu sudah pasti yaitu factor evaluation yang nilaianya antara $0-1$.

3. Proses perhitungan weight evaluation yang merupakan proses perhitungan bobot antara factor weight dan factor evaluation dengan serta penjumlahan seluruh hasil weight evaluation untuk memperoleh total hasil evaluasi.

$$
\begin{aligned}
& \mathrm{WF}=\mathrm{FW} \times \mathrm{E} \\
& \Sigma \mathrm{WE}=\Sigma(\mathrm{FW} \times \mathrm{E})
\end{aligned}
$$

Keterangan :

$\mathrm{WE}=$ Weighted Evaluation

$\mathrm{FW}=$ Factor Weight

$\mathrm{E}=$ Evaluation

$\Sigma \mathrm{WE}=$ Total Weighted Evaluation

\section{METODE PENELITIAN}

Metode yang digunakan dalam menyelesaikan masalah yang sedang di teliti, penulis sendiri menggunakan model

waterfall dalam penyelesaian perangakat lunak dan model sistem penunjang keputusan untuk penyelesaian masalah yang terjadi di sekolah SMK Cibening desa Cibingbin.

\subsection{Metode Pengembangan Sistem}

Metode pengembangan sistem yang digunakan adalah Model Waterfall. Menurut Pressman (2015:42), waterfall adalah model klasik yang bersifat sistematis, berurutan dalam membangun software.[2]

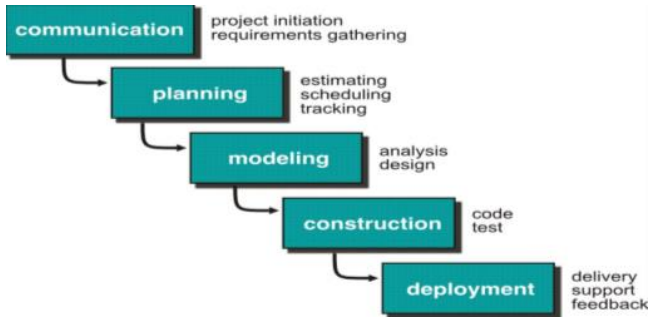

Gambar 1 Model Waterfall (Sumber : Pressman 2015:42)

a. Communication

(Project

Initiation \& Requirements

Gathering)

Diperlukan adanya komunikasi dengan customer demi memahami dan mencapai tujuan yang ingin dicapai, seperti menganalisis permasalahan yang dihadapi dan mengumpulkan data-data yang diperlukan.

b. Planning (Estimating, Scheduling, Tracking)

Tahap berikutnya adalah tahapan perencanaan yang menjelaskan tentang tugas-tugas teknis yang akan dilakukan, seperti resiko-resiko yang dapat terjadi, sumber daya yang diperlukan dalam membuat sistem, produk kerja yang ingin dihasilkan, penjadwalan kerja yang akan dilaksanakan.

\section{c. Modeling (Analysis \& Design)}

Tahapan ini adalah tahap perancangan dan permodelan yang berfokus pada perancangan tampilan interface. Tujuannya untuk lebih memahami gambaran besar dari apa yang akan dikerjakan.

\section{d. Construction (Code \& Test)}

Tahapan Construction ini merupakan proses penerjemahan bentuk desain menjadi kode atau bentuk/bahasa yang dapat dibaca oleh mesin. Tujuannya untuk menemukan kesalahan yang mungkin terjadi untuk nantinya diperbaiki.
e. Deployment (Delivery, Support, Feedback) 
Tahapan Deployment merupakan tahapan implementasi software ke customer, meliputi pemeliharaan software, perbaikan software, evaluasi software, dan pengembangan software agar sistem dapat tetap berjalan dan berkembang sesuai dengan fungsinya. (Pressman, 2015:17). [2]

\subsection{Metode Multi Factory Evaluasi Process (MFEP)}

Metode penyelasaian masalah yang digunakan dalam penelitian ini menggunakan Multifactor Evaluation Process (MFEP) yang merupakan metode kuantitatif yang menggunakan weighting system. Dalam pengambilan keputusan multifaktor, pengambil keputusan secara subyektif dan intuitif menimbang berbagai faktor yang mempunyai pengaruh penting terhadap alternatif pilihan. Dalam Multifactor Evaluation Process (MFEP) pertamatama seluruh kriteria yang menjadi faktor penting dalam melakukan pertimbangan diberikan pembobotan (weighting) yang sesuai. Langkah yang sama juga dilakukan terhadap alternatifalternatif yang akan dipilih, yang kemudian dapat dievaluasi berkaitan dengan faktor-faktor pertimbangan tersebut. Metode Multifactor Evaluation Process (MFEP) menentukan bahwa alternatif dengan perbandingan nilai tertinggi adalah solusi terbaik berdasarkan kriteria yang telah dipilih. Langkah - langkah prosedur kerja metode Multifactor Evaluation Process yaitu :

1. Menentukan faktor dan bobot faktor dimana total pembobotan harus sama dengan $1(\Sigma$ pembobotan $=1)$, yaitu factor weight.

2. Mengisikan nilai untuk setiap faktor yang mempengaruhi dalam pengambilan keputusan dari data-data yang akan diproses, nilai yang dimasukkan dalam proses pengambilan keputusan merupakan nilai objektif, yaitu sudah pasti yaitu factor evaluation.

3. Kemudian nilai factor weight dan nilai factor evaluation dikalikan untuk mendapatkan nilai weight evaluation.

4. Dari nilai weight evaluation yang di dapat, kemudian di tambahkan untuk mendapatkan nilai total weight evaluation, yang dimana nilai total weight evaluation tersebut merupakan hasil akhir dari proses kerja metode MFEP.

Penggunaan model MFEP dapat direalisasikan dengan contoh berikut

$$
\begin{aligned}
& \mathrm{WE}=\mathrm{FW} \times \mathrm{FE} \\
& \sum \mathrm{WE}=\sum(\mathrm{FW} \times \mathrm{FE}) \\
& \sum \mathrm{TWE}=\mathrm{WE} 1+\mathrm{WE} 2+ \\
& \mathrm{WE} 3+\mathrm{WE} 4, \ldots . .
\end{aligned}
$$

Keterangan : WE $=$ Weight

\begin{tabular}{|c|c|c|}
\hline $\begin{array}{l}\text { Perhitungan } \\
\text { Evaluation: }\end{array}$ & Total & Weight \\
\hline $\mathrm{TWE}=\mathrm{WE} 1$ & - WE2 + WE3 & \\
\hline $\operatorname{san}$ & TWE : Total & \\
\hline $\begin{array}{l}\text { valuation } \\
\text { valuation }\end{array}$ & WE : & \\
\hline
\end{tabular}
Evaluation $\mathbf{F W}=$ Factor Weigth $\mathbf{F E}$ = Factor Evaluation $\sum \mathbf{T W E}=$ Total Weighted Evaluation

\subsection{Analisis dan Perancangan}

\subsubsection{Flowchart MFEP}

Langkah pertama adalah dilakukannya pengumpulan data seperti raport semester ganjil dan genap kelas IX, SKHUN, dan serta hasil tes kejurusan, untuk menentukan bobot dengan cara menghitung bobot yang dikalikan 
JURNAL NUANSA INFORMATIKA

Volume 13 Nomor 2, Juli 2019
p-ISSN : 1858-3911, e-ISSN : 2614-5405

https://journal.uniku.ac.id/index.php/ilkom dengan nilai dari setiap kriteria, kemudian melakukan Weight Evaluation untuk menentukan penjurusan siswa baru, langkah terakhir yaitu menentukan penjurusan dengan referensi dari hasil Weight Evaluation berikut flowchart Seperti yang dapat dilihat pada gambar 1 .

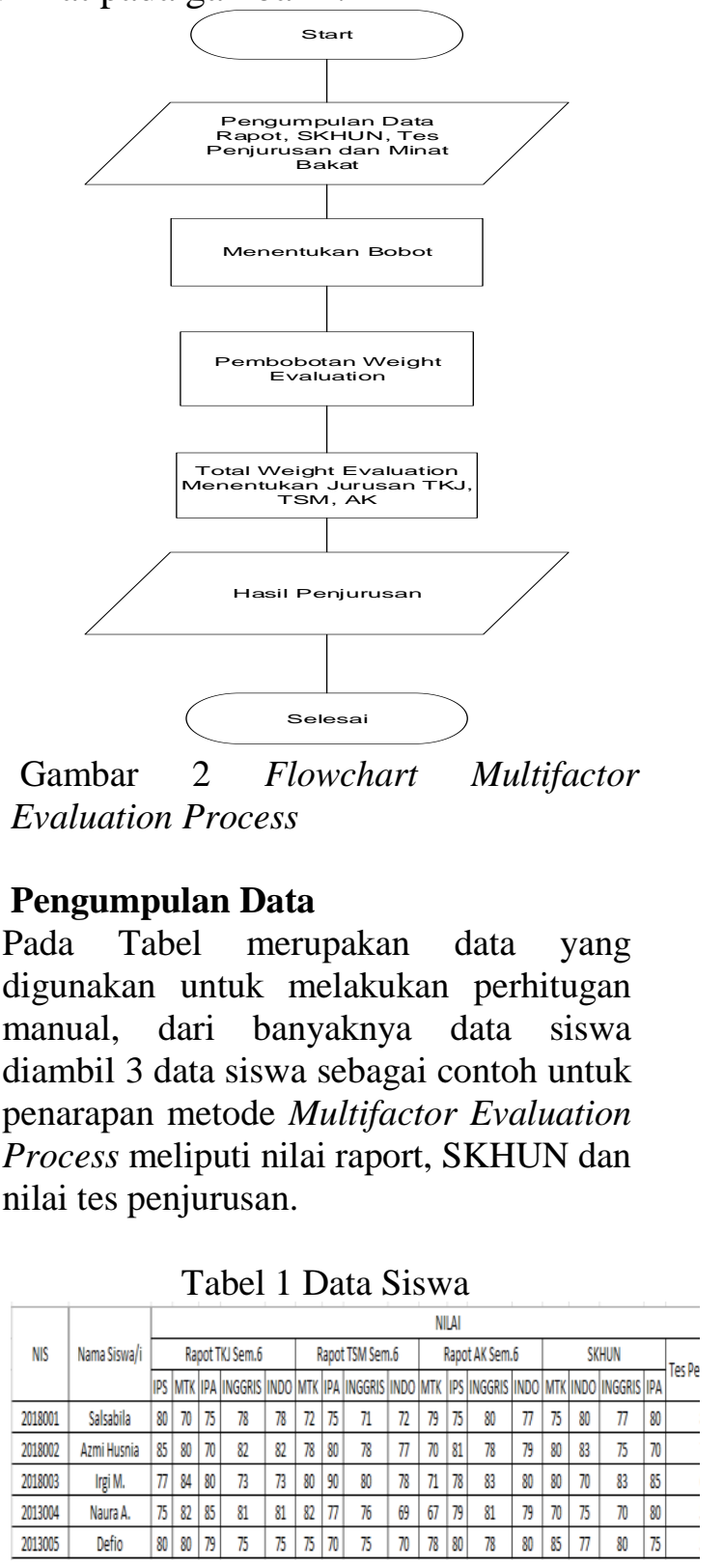

\section{Menentukan Bobot}

Menentukan bobot di dapat berdasarkan hasil diskusi dengan pihak sekolah yakni guru program studi di SMK Cibening, dalam penelitian ini penulis memiliki 3 Kriteria utama untuk proses perhitungan diantaranya seperti pada tabel 2 dibawah ini.

Tabel 2 Bobot

\begin{tabular}{|c|c|c|}
\hline No & Kriteria & Bobot \\
\hline 1 & Raport & 0,4 \\
\hline 2 & SKHUN & 0,4 \\
\hline 3 & Tes Kejurusan & 0,2 \\
\hline
\end{tabular}

Dari tabel diatas berdasarkan observasi dan wawancara yang dilakukan oleh penulis dengan pihak sekolah yang terkait khususnya guru program studi dalam menentukan kriteria tes penjurusan dan menentukan bobot dari masing-masing kriteria.

Kesimpulannya besar kecilnya nilai bobot yang ditentukan sangat berpengaruh besar dalam proses penjurusan.

\subsubsection{Pemboboton Weight Evaluation}

Merupakan proses perhitugan kriteria bobot antara factor weight (Raport 0,4, SKHUN 0,4 dan Tes Psikotes 0,2) dan factor evaluation yang terdiri dari nilai raport, nilai SKHUN dan nilai tes penjurusan.

Tabel 3 Pembobotan Weight Evaluation

\begin{tabular}{|c|c|c|c|c|c|c|c|c|c|c|c|c|c|c|c|c|c|}
\hline \multirow{3}{*}{ Nis } & \multirow{3}{*}{ Namasionali } & \multicolumn{16}{|c|}{ NIAI } \\
\hline & & \multicolumn{3}{|c|}{ RepotTUSem.6 } & \multicolumn{4}{|c|}{ RapoctTSM Sem.6 } & \multicolumn{4}{|c|}{ Rapotatasem.6 } & \multicolumn{4}{|c|}{ SCHN } & \multirow{2}{*}{ Tespenivusar } \\
\hline & & 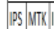 & $A \mathbb{M N}$ & & $n \pi x$ & & GOAS & INDO & MTR & & IGOPPS & INDO & & NoO & W NG69:5 & $\mathbb{P A}$ & \\
\hline 2018001 & Sassbila & \begin{tabular}{|l|}
32 \\
\end{tabular} & & 31.2 & 28.8 & 30 & 8.4 & 28.8 & 316 & 30 & 32 & 30.8 & 30 & 32 & 308 & 32 & 16 \\
\hline 2018002 & RziHiHssia & 1732 & & 32.8 & 31.2 & 32 & 1.2 & 30.8 & 28 & 324 & 31.2 & 31.6 & 32 & 332. & 30 & 28 & 14 \\
\hline 2018003 & Ig gi 1 . & 3028336 & & 29.2 & 32 & 36 & 32 & 31.2 & 28.4 & 311 & 33.2 & 32 & 32 & 28 & 332 & 34 & 12 \\
\hline 201304 & Nava A. & 30328 & & 24 & 328 & 30.8 & 0.4 & 27.6 & 268 & 316 & 324 & 31.6 & 28 & 30 & 28 & 32 & 10 \\
\hline 201305 & Defio & 3232 & & 30 & 30 & 28 & 30 & 28 & 312 & 32 & 312 & 32 & 34 & 3018 & 32 & 30 & 10 \\
\hline
\end{tabular}

Berikut perhitungan terhadap Weight Evaluation dari data siswa bernama Salsabila, Azmi Husnia, Irgi M. , Naura A., Defio dari tabel diatas dengan menggunakan metode Multifactor Evaluation Process :

\section{SALSABILA}

\begin{tabular}{|c|c|c|c|c|c|c|c|c|c|c|c|c|c|c|c|c|}
\hline \multicolumn{17}{|c|}{ NILAI } \\
\hline \multicolumn{4}{|c|}{ Rapot TKJ Sem,6 } & \multicolumn{4}{|c|}{ RapotTSM Sem, 6} & \multicolumn{4}{|c|}{ Rapot AK Sem.6 } & \multicolumn{2}{|l|}{ SKHUN } & & & \multirow{2}{*}{ Tes Penjurusan } \\
\hline & \begin{tabular}{l|l} 
MTK & $\mid P A$ \\
PA
\end{tabular} & INGGRIS & INDO & MTK & & INGGRIS & INDO & MTK & IPS & INGGRIS & INDO & MTK & INDO & \begin{tabular}{|l|} 
INGGRIS \\
\end{tabular} & & \\
\hline 80 & \begin{tabular}{l|l|}
70 & 75 \\
\end{tabular} & 78 & 78 & 72 & 75 & 71 & 72 & 79 & 75 & 80 & 77 & 75 & 80 & 77 & 80 & 80 \\
\hline
\end{tabular}


JURNAL NUANSA INFORMATIKA

Volume 13 Nomor 2, Juli 2019

a. Weight Evaluation Jurusan TKJ

Nilai Raport semester 6 :

$(80 \times 0,4)+(70 \times 0,4)+(75 \times 0,4)+($

$78 \times 0,4)=(32)+(28)+(30)+(31.2)=$

121.2

Surat Keterangan Hasil Ujian Nasional (SKHUN)

$(75 \times 0,4)+(80 \times 0,4)+(77 \times 0,4)+$ $(80 \times 0,4)=(30)+(32)+(30.8)+(32)=$ 124,8

Nilai Penjurusan

$(80 \times 0,2)=\mathbf{1 6}$

b. Weight Evaluation TSM

Nilai Raport semester 6

$(72 \times 0,4)+(75 \times 0,4)+(71 \times 0,4)+($

$72 \times 0,4)=(28,8)+(30)+(28,4)+$

$(28,8)=\mathbf{1 1 6}$

Surat Keterangan Hasil Ujian

Nasional (SKHUN)

$(75 \times 0,4)+(80 \times 0,4)+(77 \times 0,4)+($

$80 \times 0,4)=$

$(30)+(32)+(30.8)+(32)=\mathbf{1 2 4 , 8}$

Nilai Penjurusan

$(80 \times 0,2)=\mathbf{1 6}$

c. Weight Evaluation AK

Nilai Raport semester 6

$(72 \times 0,4)+(75 \times 0,4)+(71 \times 0,4)$ $+(72 \times 0,4)$

$(28,8)+(30)+(28,4)$

$+(28,8)=\mathbf{1 1 6}$

Surat Keterangan Hasil Ujian Nasional (SKHUN)

$(75 \times 0,4)+(80 \times 0,4)+(77 \times 0,4)$

$+(80 \times 0,4)$

$(30)+(32)+(30.8)+($

$32)=124,8$

Nilai Penjurusan

$(80 \times 0,2)=\mathbf{1 6}$

\section{AZMI HUSNIA}

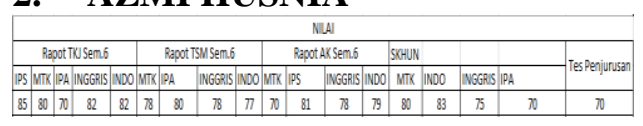

\section{a. Weight Evaluation Jurusan} TKJ

Nilai Raport semester 6 :

$(85 \times 0,4)+(80 \times 0,4)+(70 \times 0,4)$ $+(82 \times 0,4)$

$(34)+(32)+\left(\begin{array}{l}28 \\ 3\end{array}\right)+($

$32.8 \quad)=\mathbf{1 2 6 . 8}$

Surat Keterangan Hasil Ujian Nasional (SKHUN)

$(80 \times 0,4)+(83 \times 0,4)+(75 \times 0,4)$

$+(70 \times 0,4)$
p-ISSN : 1858-3911, e-ISSN : 2614-5405

https://journal.uniku.ac.id/index.php/ilkom

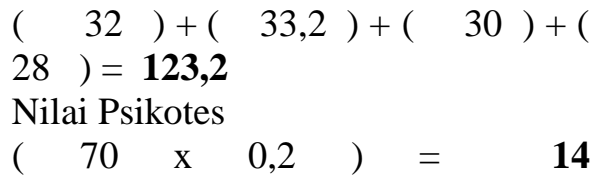

b. Weight Evaluation Jurusan TSM

Nilai Raport semester 6 :

$(78 \times 0,4)+(80 \times 0,4)+(78 \times 0,4)$

$+(77 \times 0,4)$

$(31.2)+(32)+\left(\begin{array}{l}31.2\end{array}\right)$

$+(30.8)=\mathbf{1 2 5 . 2}$

Surat Keterangan Hasil Ujian

Nasional (SKHUN)

$(80 \times 0,4)+(83 \times 0,4)+(75 \times 0,4)$

$+(70 \times 0,4)$

$(32)+(33,2)+(30)+($

$28)=\mathbf{1 2 3 , 2}$

Nilai Penjurusan

$(70 \times 0,2)=\mathbf{1 4}$

\section{c. Weight Evaluation AK}

Nilai Raport semester 6 :

$(79 \times 0,4)+(75 \times 0,4)+(80 \times 0,4)$ $+(77 \times 0,4)$

$(31.6)+(30)+(32)+$

$(30.8)=\mathbf{1 2 4 . 4}$

Surat Keterangan Hasil Ujian

Nasional (SKHUN)

$(80 \times 0,4)+(83 \times 0,4)+(75 \times 0,4)$

$+(70 \times 0,4)$

$(32)+(33,2)+(30)+($

$28)=\mathbf{1 2 3 , 2}$

Nilai Penjurusan

$(70 \times 0,2)=\mathbf{1 4}$

\section{IRGI M.}

\begin{tabular}{|c|c|c|c|c|c|c|c|c|c|c|c|c|c|c|c|c|}
\hline \multicolumn{17}{|c|}{ NILAI } \\
\hline \multicolumn{4}{|c|}{ Rapot TK Sem.6 } & \multicolumn{4}{|c|}{ Rapot TSM Sem.6 } & \multicolumn{4}{|c|}{ RapotAKSem.6 } & \multicolumn{2}{|c|}{ SKHUN } & \multirow[b]{2}{*}{ INGGRIS } & & \multirow{2}{*}{ Tes Penjurusan } \\
\hline PS $/$ MT: & \begin{tabular}{|l|l|}
$T K$ & PA \\
\end{tabular} & INGGRIS & $\mathrm{IND}$ & MT & IPA & INGGRIS & INDO & MTK & IPS & INGGRI: & INDO & \begin{tabular}{|l|} 
MTK \\
\end{tabular} & INDO & & & \\
\hline $\begin{array}{ll}78 & 84 \\
\end{array}$ & \begin{tabular}{|l|l|}
4 & 80 \\
\end{tabular} & 73 & 73 & 80 & 90 & 80 & 78 & 71 & 78 & 83 & 80 & 80 & 70 & 83 & 85 & 60 \\
\hline
\end{tabular}

\section{a. Weight Evaluation Jurusan TKJ}

Nilai Raport semester 6 :

$(77 \times 0,4)+(84 \times 0,4)+(80 \times 0,4)+(73 \times$ $0,4)=(30.8)+(33.6)+(32)+(29.2)=\mathbf{1 2 5 . 6}$

Surat Keterangan Hasil Ujian Nasional (SKHUN)

$(80 \times 0,4)+(70 \times 0,4)+(83 \times 0,4)+(85 \times$ $0,4)=(32)+(33,2)+(33.4)+(34)=132.6$

Nilai Penjurusan $(60 \times 0,2)=12$

b. Weight Evaluation Jurusan TSM

Nilai Raport semester 6 :

$(80 \times 0,4)+(90 \times 0,4)+(80 \times 0,4)+(78 \times$

$0,4)=(32)+(36)+(32)+(31.2)=\mathbf{1 3 1 . 2}$ 
Surat Keterangan Hasil Ujian Nasional (SKHUN)

$(80 \times 0,4)+(70 \times 0,4)+(83 \times 0,4)+(85$ $\mathrm{x} 0,4)=(32)+(33,2)+(33.4)+(34)=\mathbf{1 3 2 . 6}$

Nilai Penjurusan $(60 \times 0,2)=12$

c. Weight Evaluation Jurusan AK

Nilai Raport semester 6 :

$(71 \times 0,4)+(78 \times 0,4)+(83 \times 0,4)+(80 \times$ $0,4)=(28.4)+(31.2)+(33.2)+(32)=\mathbf{1 2 4 . 8}$

Surat Keterangan Hasil Ujian Nasional (SKHUN)

$(80 \times 0,4)+(70 \times 0,4)+(83 \times 0,4)+(85 \times$ $0,4)(32)+(33,2)+(33.4)+(34)=\mathbf{1 3 2 . 6}$

Nilai Penjurusan

$(60 \times 0,2)=\mathbf{1 2}$

$(67 \times 0,4)+(79 \times 0,4)+(81 \times 0,4)+(79 \times$

$0,4)=(26.8)+(31.6)+(32.4)+(31.6)=\mathbf{1 2 2 . 4}$

Surat Keterangan Hasil Ujian Nasional (SKHUN)

$(70 \times 0,4)+(75 \times 0,4)+(70 \times 0,4)+(80 \times$

$0,4)=(28)+(30)+(28)+(32)=\mathbf{1 1 8}$

Nilai Penjurusan

$(50 \times 0,2)=\mathbf{1 0}$

$(30)+(28)+(30)+(28)=\mathbf{1 1 6}$

Surat Keterangan Hasil Ujian Nasional (SKHUN)

$(85 \times 0,4)+(77 \times 0,4)+(80 \times 0,4)+(75 \times$

$0,4)=(34)+(30.8)+(32)+(30)=118$

Nilai Penjurusan

$(50 \times 0,2)=\mathbf{1 0}$

3. Total Weight Evaluation Menentukan Jurusan TKJ, TSM atau AK

Dari perhitungan weight evaluation, tahap selanjutnya menentukan penjurusan adalah dengan perhitungan total weight evaluation yaitu menambahkan hasil yang diperoleh sebelumnya, kemudian hasil dari perhitungan tersebut akan dicari nilai yang besar, apabila faktor TKJ lebih besar dibandingkan nilai faktor TSM maka siswa tersebut tergolong dalam penjurusan TKJ, begitupun sebaliknya apabila faktor AK lebih besar dibandingkan nilai faktor TKJ maka siswa tersebut tergolong dalam penjurusan AK.

a. SALSABILA

a) Total Weight Evaluation TKJ

$\sum \mathrm{WE}=\sum_{\text {Raport Semester } 6+\sum}$ SKHUN $+\sum$ Nilai Penjurusan $\sum \mathrm{WE}=121.2+124.8+16=\mathbf{2 6 2}$

b) Total Weight Evaluation TSM
p-ISSN : 1858-3911, e-ISSN : 2614-5405

https://journal.uniku.ac.id/index.php/ilkom

$\sum_{\mathrm{WE}}=\sum_{\text {Raport }}$ Semester $6+\sum$

SKHUN $+\sum$ Nilai Penjurusan

$\sum_{\mathrm{WE}}=116+124.8+16=\mathbf{2 5 6 . 8}$

c) Total Weight Evaluation AK

$\sum \mathrm{WE}=\sum_{\text {Raport }}$ Semester $6+\sum$

SKHUN $+\sum$ Nilai Penjurusan

$\sum \mathrm{WE}=124.4+124.8+16=\mathbf{2 6 5 . 2}$

b. AZMI HUSNIA

a) Total Weight Evaluation Jurusan

TKJ

$\sum \mathrm{WE}=\sum_{\text {Raport }}$ Semester $6+\sum$

SKHUN $+\sum$ Nilai Penjurusan

$\sum \mathrm{WE}=126.8+123.2+14=\mathbf{2 6 4}$

b) Total Weight Evaluation Jurusan TSM

$\sum \mathrm{WE}=\sum_{\text {Raport }}$ Semester $6+\Sigma$

SKHUN $+\sum$ Nilai Penjurusan

$\sum_{\mathrm{WE}}=125.2+123.2+14=\mathbf{2 6 2 . 4}$

c) Total Weight Evaluation Jurusan AK

$\sum \mathrm{WE}=\sum_{\text {Raport }}$ Semester $6+\sum$

SKHUN $+\sum$ Nilai Penjurusan

$\sum \quad \mathrm{WE}=124.4+123.2+14=261.6$

c. IRGI M.

a) Total Weight Evaluation Jurusan TKJ

$\sum \mathrm{WE}=\sum_{\text {Raport }} 6+\sum_{\mathrm{SKHUN}}+\sum$ Nilai Penjurusan

$\sum \mathrm{WE}=125.6+132.6+12=\mathbf{2 7 0 . 2}$

b) Total Weight Evaluation Jurusan TSM

$\sum \mathrm{WE}=\sum$ Raport Semester $6+\Sigma$

SKHUN $+\sum$ Nilai Penjurusan

$\sum \mathrm{WE}=131.2+132.6+12=\mathbf{2 7 5 . 8}$

c) Total Weight Evaluation Jurusan AK

$\sum \mathrm{WE}=\sum_{\text {Raport Semester } 6}+\Sigma$

SKHUN $+\sum$ Nilai Penjurusan

$\sum \mathrm{WE}=124.8+132.6+12=\mathbf{2 6 9 . 4}$

\section{Hasil Penjurusan}

Hasil dari total weight evaluation akan dibandingkan, jika salah satu dari keduanya memiliki nilai lebih tinggi maka siswa tersebut akan masuk kedalam jurusan tersebut, berikut merupakan tabel perbandinga hasil penjurusan dari kedua 
JURNAL NUANSA INFORMATIKA

Volume 13 Nomor 2, Juli 2019

total weight evaluation yang di tunjukan pada tabel 4:

Tabel 4 hasil penjurusan

\begin{tabular}{|l|l|l|l|l|c|}
\hline No & $\begin{array}{l}\text { Nama } \\
\text { Siswa }\end{array}$ & $\begin{array}{l}\text { Nilai } \\
\text { Total } \\
\text { Weight } \\
\text { Evaluatio } \\
\text { n TKJ }\end{array}$ & $\begin{array}{l}\text { Nilai } \\
\text { Total } \\
\text { Weight } \\
\text { Evaluatio } \\
\text { n TSM }\end{array}$ & $\begin{array}{l}\text { Nilai } \\
\text { Total } \\
\text { Weight } \\
\text { Evaluatio } \\
\text { n AK }\end{array}$ & Jurusan \\
\hline 1 & Salsabila & 262 & 256.8 & 265.2 & AK \\
\hline 2 & $\begin{array}{l}\text { Azmi } \\
\text { Husnia }\end{array}$ & 264 & 262.4 & 261.6 & TKJ \\
\hline 3 & Irgi M. & 270.2 & 275.8 & 269.4 & TSM \\
\hline
\end{tabular}

\section{HASIL DAN PEMBAHASAN}

\section{Halaman Utama Admin Guru BK}

Merupakan halaman utama dari Merupakan halaman utama dari admin guru BK dalam halaman ini terdapat beberapa menu diantaranya menu data siswa, data rapot, data surat keterangan hasil ujian nasional (SKHUN) data soal, data kriteria, dan menu perhitungan multifactor evaluation process (MFEP) halaman ini dapat dilihat pada gambar 3 dibawah ini.

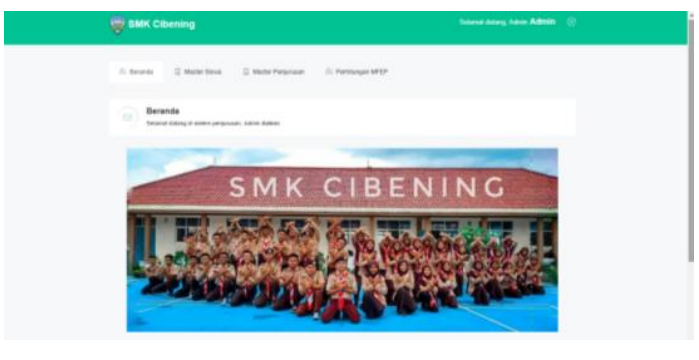

Gambar 3 Halaman Utama Admin

\section{Halaman Tes Kejurusan}

Pada tampilan dibawah ini siswa diwajibkan mengisi atau memilih jawaban pilihan ganda yang diberikan oleh sistem, yang diselenggarakan oleh pihak sekolah. Dapat dilihat pada gambar 4 dibawah ini.

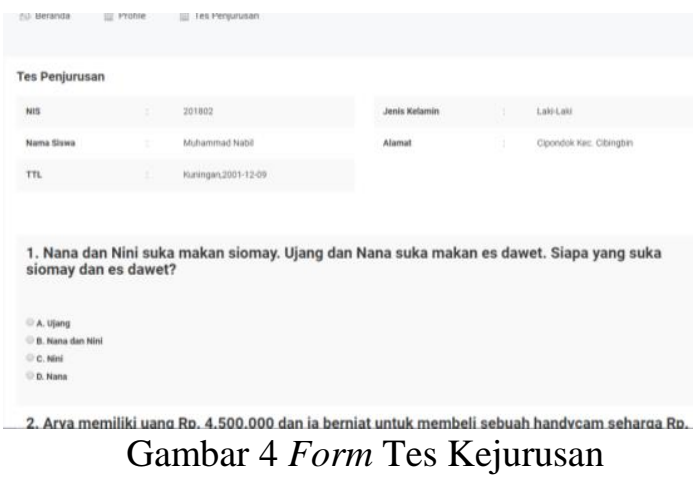

\section{Halaman Laporan Hasil Penjursan}

Pada tampilan ini merupakan hasil akhir dari proses penjurusan dengan menggunakan metode Multifactor Evaluation Process, seperti pada gambar 5 dibawah ini.

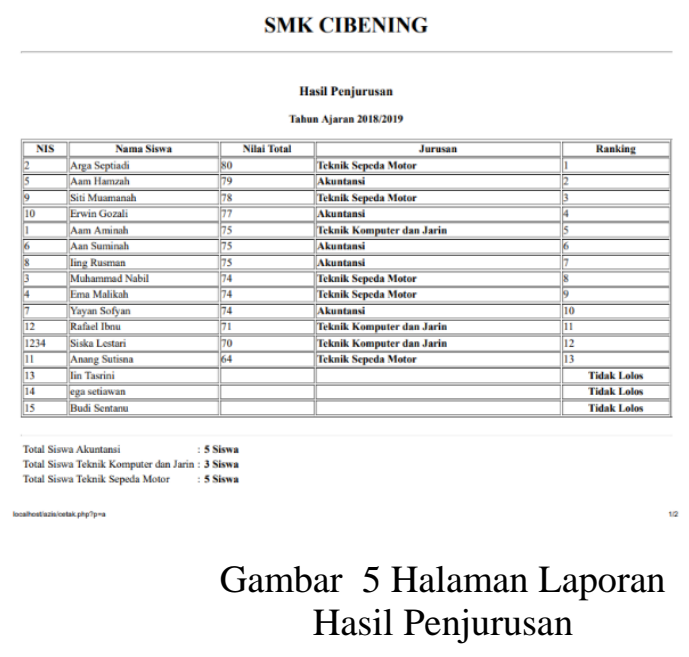

\section{KESIMPULAN}

Berdasarkan hasil penelitian yang telah dilakukan dapat disimpulkan beberapa hal sebagai berikut.

1. Aplikasi Sistem Informasi Penjurusam Siswa telah berhasil dibangun dengan menggunakan bahasa pemrograman PHP dan basis data MySQL.

2. Sistem pendukung keputusan dengan menggunakan metode Multi Factor Evaluation Process (MFEP) telah berhasil dibangun untuk membantu SMK Cibening dalam penjurusan siswa sesuai dengan kebutuhan 
3. Hasil pengujian fungsional menunjukan bahwa fungsi-fungsi yang terdapat pada aplikasi berjalan dengan baik dan sesuai dengan kebutuhan dan rancangan.

4. Sistem dapat berjalan dengan baik dengan memberikan penempatan jurusan sesuai berdasarkan kemampuan siswa dan jurusan yang diminati

\section{SARAN}

Beberapa saran yang diberikan setelah dilakukan penelitian ini untuk pengembangan lebih lanjut adalah sebagai berikut.

1. Sistem dapat dikembangkan dengan menambahkan ujian on-line untuk penggantian tes tertulis untuk mempermudah dalam memasukkan nilai.

2. Perbaikan fungsi-fungsi yang terdapat pada aplikasi untuk memaksimalkan tujuan dari pengembangan aplikasi dan kinerja aplikasi.

3. Perbaikan pada tampilan aplikasi sehingga menjasi aplikasi lebih menarik.

4. Sistem dapat dikembangkan hingga sistem dapat memberikan rekomendasi jurusan yang lebih sesuai untuk pendaftar.

5. User interface yang dibangun masih tampak sederhana, sehingga perlu dibuat rancangan interface yang lebih menarik.

\section{DAFTAR PUSTAKA}

[1] Martuasa, (2015), Sistem Pendukung Keputusan Penentuan Siswa Berprestasi Dan Penempatan Kelas Berdasrkan Peringkat Menggunakan Multifactor Process, Medan : STMIK Budi Darma Medan.

[2] Pressman, Roger, S. (2015), Software Engineering: A Pracititioner's Approach, Fifth Ed.
New York, McGraw-Hill Book Company.

[3] Ahmad Khaidir, (2014). Sistem Pendukung Keputusan Penyeleksian Calon Siswa Baru di SMA Negri 1 Badar dengan Metode Multifactor Evaluation Process (MFEP) : Jurnal Pelita Informatika Budi Darma.

[4] Krismiaji, (2015), "Sistem Informasi Akuntansi", Edisi keempat, UPP STIM YKPN, Yogyakarta.

[5] Romney, Marshall B. dan Steinbart, (2015), "Sistem Informasi Akuntansi", Edisi 13, alihbahasa: Kikin Sakinah Nur Safira dan Novita Puspasari, Salemba Empat, Jakarta.

[6] Kadir (2014), "Sistem Informasi Akuntansi", Edisi kedua, BPFE Yogyakarta.

[7] Wibowo. (2011) ,MADM-TOOLS: Aplikasi Uji Sensitivitas Unutk Model MADM Menggunakan Metode SAW dan TOPSIS. Seminar Nasional Aplikasi Teknologi Informasi 2011, ISSN: 1907-5022 hal , Universitas Islam Indonesia, Yogyakarta.

[8] Utami, 2012. Penerapan Algoritma Iterative Dichotomiser Three untuk Pemilihan Dosen Pembimbing. Universitas Kristen Satya Wacana: Jawa Tengah.

[9] Nofriansyah, D. (2014).Buku Konsep Data Mining vs Sistem Pendukung Keputusan. Yogyakarta: Deepublish.

[10] Yourdon, Edward, "Modern Structured Analysis", Prentice-Hall International Inc., Englewood Cliffs, New Jersey, 1989

[11] DeMarco, Tom., "Structured Analysis and System Specifications", Prentice-Hall, New York, 1979. 
JURNAL NUANSA INFORMATIKA

Volume 13 Nomor 2, Juli 2019
p-ISSN : 1858-3911, e-ISSN : 2614-5405

https://journal.uniku.ac.id/index.php/ilkom

[12] Kristanto, Andri. 2008.

Perancangan Sistem Informasi dan

Aplikasinya. Yogyakarta: Gava Media.

[13] Rifa Turaina, 2016, Sistem Penunjang Keputusan Penerimaan Calon Tenaga Honorer Di Sma N 1 Junjung Sirih Kab. Solok Menggunakan Metode Multifaktor Evaluasi Proses (Mfep), Padang : STMIK Indonesia Padang.

[14] P Joko Subagyo, 2011. Metodologi Peneliti Dalam Teori dan Praktek. Jakarta : Aneka Cipta. 